\title{
Giving-up diversity (GUDiv): top-down effects of foraging decisions on local, landscape and regional biodiversity of resources
}

\author{
Jana Eccard ${ }^{1}$, Clara Ferreira ${ }^{1}$, Andres Peredo Arce $^{1}$, and Melanie Dammhahn² \\ ${ }^{1}$ University of Potsdam \\ ${ }^{2}$ Universitat Potsdam
}

January 20, 2021

\begin{abstract}
Foraging by consumers has direct effects on the community of their resource species, and may serve as a biotic filtering mechanism of diversity. Determinants of foraging behaviour may thus have cascading effects on abundance, diversity, and functional trait composition of the resource community. Here we propose giving-up diversity (GUDiv) as a novel concept and simple measure to quantify community effects of foraging at multiple spatial diversity scales. GUDiv provides a framework linking theories of adaptive foraging behaviour with community ecology. In experimental resource landscapes we showcase effects of patch residency of foraging wild rodents on $\alpha$-GUDiv, $\beta$-GUDiv and $\gamma$-GUDiv, and on functional trait composition of resources. Using GUDiv allows for prediction-based investigation of cascading indirect predation effects (ecology of fear) across multiple trophic levels, of feedbacks between functional trait composition of resource and consumer communities, and of effects of inter-individual differences among foragers on the diversity of resource communities.
\end{abstract}

\section{Hosted file}

EccadetalGUDiv.pdf available at https://authorea.com/users/390649/articles/504916-giving-updiversity-gudiv-top-down-effects-of-foraging-decisions-on-local-landscape-and-regional-

biodiversity-of-resources 